Journal of Engineering and Applied Sciences 15 (4): 948-955, 2020

ISSN: $1816-949 \mathrm{X}$

(C) Medwell Journals, 2020

\title{
Web Service Selection Model using a Hybrid Approach
}

\author{
Sandile Thamie Mhlanga, Manoj Lall and Sunday O. Ojo \\ Department of Computer Science, Tshwane University of Technology, \\ 2 Aubrey Matlakala Street, Soshanguve, Pretoria, South Africa
}

\begin{abstract}
Web services have enjoyed rapid acceptance in recent years. The motivating factors for its wide acceptance is the ease and cost effectiveness in application integration. The utilization of a web services based application depends not only on meeting its functional requirements but also its non-functional requirements. As the numbers of web services offering similar functionality and varying degrees of Quality of Service (QoS) are increasing, service consumers face a dilemma in selecting the most appropriate one from the pool. To address this issue, this study proposes a model for determining a suitable web service by integrating AHP (Analytic Hierarchy Process) and VIKOR (Vlsekriterjumskaoptimizacija I Kompromisno Resenje) methods. Using AHP, the weights assigned to QoS criteria are computed. There after, the ranking of the web services, according to a user preferred criteria, is obtained using VIKOR method. Finally, in order to demonstrate the validity of the proposed method, data from the QWS data set are used in a service selection. The results illustrate that Google search service performed better than other web search services under the selected QoS requirements.
\end{abstract}

Key words: Web services, web services selection, quality of service, multi-criteria decision making, AHP, VIKOR

\section{INTRODUCTION}

A large number of organizations have and continue to reap the benefits of the web by making their applications available to their customers and partners through a combination of interactive interfaces and dynamically generated web pages. A subsequent step in the evolution of web technologies is the emergence of web services (Aiello and Giorgini, 2004). There are several definitions of web services but most agree on stating that web services are software entities available on the web (through a URI), communicating through XML messages over an internet transport protocol and whose capabilities and modus operandi are described in XML (Benatallah et al., 2005; Lall et al., 2012) in comparison to its predecessor technologies i.e., CORBA, DCOM or RMI, web services are relatively new model for distributed computing. Web services offer a programming model for building distributed applications using open internet standards. Centring on open internet standards, web services address many of the interoperability issues associated with its predecessor technologies. Unlike previous concepts in distributed computing-objects or components, web services are more modular and self-contained. It offers reusable functionality that is contractually defined in a service description. Each service provides access to a well-defined collection of functionality and the system as a whole is designed and implemented as a set of interactions amongst these services (Brown et al., 2002; Lall et al., 2010).

A major requirement of web services applications is to operate in such a way that they are functionally reliable and deliver consistent service at a variety of levels. This requirement does not focus only on the functional properties of services but also on the Quality of Service (QoS). QoS, also known as non-functional properties denotes the quality aspects of a web service such as execution time, throughput, availability, reliability and latency (Kaewbanjong and Intakosum, 2015; Lall et al., 2010). In the context of web services, considerations of the QoS attributes are crucial for a number of reasons: firstly, autonomous services depend on one another for their functioning and they need to be aware of each other's QoS, secondly, a service requester may decide on the use of a particular service-depending on its non-functional properties. Similarly, a service provider may offer the same function with a different QoS for example, different prices for the same service but with different levels of security considerations (Aiello and Giorgini, 2004; Mani and Nagarajan, 2002; Lall, 2013). Hence, this study incorporates QoS attributes in the proposed model for web service selection.

The task of selecting a web service emanates when there is a list of discovered web services which can fulfil a consumer's requirements and one of those services is to

Corresponding Author: Manoj Lall, Department of Computer Science, Tshwane University of Technology, 2 Aubrey Matlakala Street, Soshanguve, Pretoria, South Africa 
be chosen and returned to the service consumer. Selecting a web service based on consumer preference is a complex problem due to the diverse consumer requirements-one consumer may require a service offering high performance but with a low cost whereas another consumer the other may require high security and high availability (Sun et al., 2013). Therefore, choosing the right web service does not only include the problem of discovering services on the basis of their functionalities but also assessing the quality aspects of those services (Dragoni, 2009). In this study, we report on the use of AHP and VIKOR in combination for deciding on a particular web service. The AHP is a theory of measurement through pairwise comparison and relies on judgment of experts to derive priority scales (Saaty, 2008). AHP focuses on synthesizes people's subjective judgement by integrating qualitative and quantitative analysis to achieve quantitative decision-making (Russo and Camanho, 2015). The method is not only applicable to situation where uncertainty and subjective information exist but also allows logical use of experience, insight and intuition when analysing an issue (Zuo et al., 2008). On the other hand, VIKOR is a ranking technique, employed to evaluate the performance of all considered alternatives and obtain a compromised solution to the selection problem (Opricovic and Tzeng, 2004). A compromised solution arises when a selection problems includes several non-commensurable and conflicting criteria and has no clear solution that satisfies all criteria simultaneously (Chang, 2014; Athawale et al., 2010). In VIKOR, a compromise ranking method is introduced as an applicable technique to deal with multi-criteria decision making problems (Tzeng et al., 2002).

This study presents an evaluation approach using AHP and VIKOR to solve the problem of conflicting criteria or criteria with different QoS requirements in web services based applications. The weighted valuesfor the QoS requirements are determined by AHP based on expert's knowledge to capture qualitative as well as quantitative information in the proposed model. VIKOR is then applied on the weighted values to introduce an aggregating function, representing the ranking of the possible solutions. The highest ranked alternative is the closest to the ideal solution.

Literature review: As the number of published web services increases, selecting a suitable web service that fulfils the service consumer's needs is a core and challenging task in Service Oriented Architecture (SOA) based applications (Purohit and Kumar, 2018). Frequently, the only differentiating factor between services satisfying the functional needs of a consumer may be their QoS attributes (Aljazzaf et al., 2016). Hence, this study places a great focus on the QoS attributes of a web service in the selection process.
From literature, many approaches have been dedicated to web service selection problem (Kumar and Zayaraz, 2011; Kumar and Kumar, 2016; Purohit and Kumar, 2018). For instance, Kumar and Zayaraz (2011) have focused on AHP for web services selection. Similarly, Kumar and Kumar (2016) have proposed fuzzy AHP approach for the selection process. In another research, Purohit and Kumar (2018) have applied the PROMETHEE (The Preference Ranking and Organization METHod for Enrichment Evaluation) method for deciding on a suitable web service. Various other researchers such as Belouaar et al. (2017), Maheswari and Karpagam (2015) and Zhang et al. (2011) have applied the TOPISIS algorithms in the selection process. In addition to the above mentioned researchers, several other researchers have applied hybrid techniques in addressing decision making problem semanating in various fields. For instance, Buyukozkan and Gorener (2015) proposed an integrated multi-criteria decision making approach to effectively evaluate product development partners using AHP and VIKOR. In another instance, a multi-criteria decision modelling is proposed for determining the most preferred bidding mark-up competitive bidding situation (Liu and Yan, 2007). A hybrid model to evaluate restaurant location alternatives by applying AHP and VIKOR is proposed by Tzeng et al. (2002). From the extensive literature review conducted, no research has been reported on applying the AHP and VIKOR hybrid method for the selection of web services which this research focuses on. In this study, we present the research methodology of our proposed web service selection model.

\section{MATERIALS AND METHODS}

As evident from information presented in the section 1 , the task of deciding on a particular web service is a complex one. We first apply AHP to determine the importance of each QoS criterion by determining their weights. Thereafter, we apply the VIKOR method to obtain a ranking of the Web services from the most appropriate to the least. Details of the process are depicted in Fig. 1.

As an initial step, a consumer is obligatory to establish priorities for the required QoS attributes by adjudicating them in pairs for their relative importance. To assist in establishing the relative importance of the QoS attributes, Saaty 1-9 preference scale (shown in Table 1) is used (Saaty, 2008). In addition, the selection problem is decomposed into structural hierarchy by defining criteria and sub-criteria for the evaluation. Steps 2-7 are related to AHP.

\section{Step 2: Construct a pairwise comparison matrix}

Assuming $\mathrm{n}$ attributes, the pairwise comparison of attributes $i$ with attribute $j$ yields a square matrix $A_{n x n}$ 


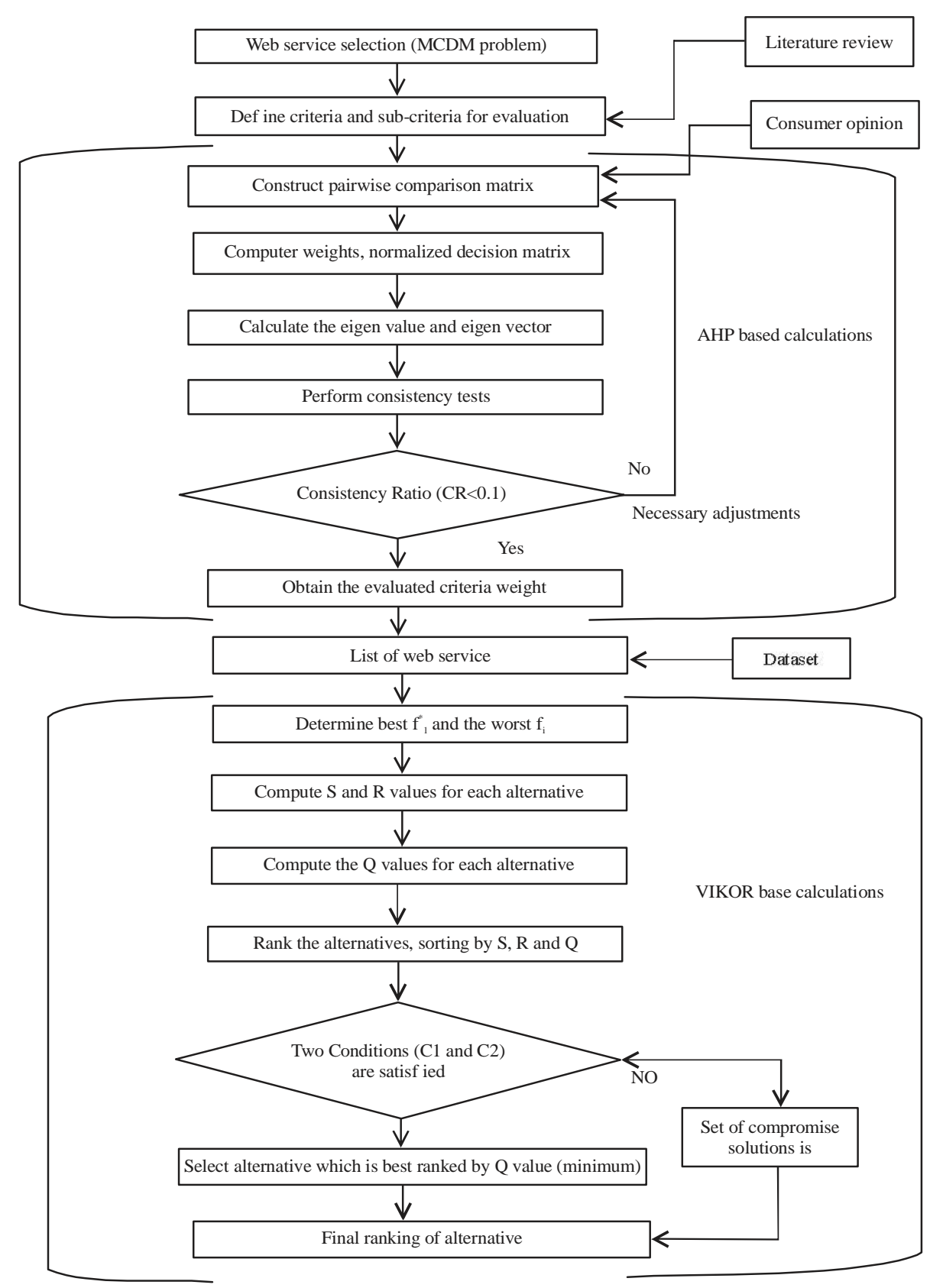

Fig. 1: Flowchart of the proposed model for web service selection

Table 1: Saaty's pairwise comparison scale (Saaty, 1987)

\begin{tabular}{ll}
\hline Scale of preference & Compare factor of $i$ and $j$ \\
\hline 1 & Equally important \\
3 & Marginally important \\
5 & Strongly important \\
7 & Very strongly important \\
9 & Extremely important \\
$2,4,6,8$ & Intermediate value between adjacent scales \\
\hline
\end{tabular}

where $\mathrm{a}_{\mathrm{ij}}$ denote the comparative importance of attribute $\mathrm{i}$ with respect to attribute $\mathrm{j}$. In the matrix, $\mathrm{a}_{\mathrm{ij}}=1$ when $\mathrm{i}=\mathrm{j}$ and $\mathrm{a}_{\mathrm{ji}}=1 / \mathrm{a}_{\mathrm{ij}}$ (Benitez et al., 2011):

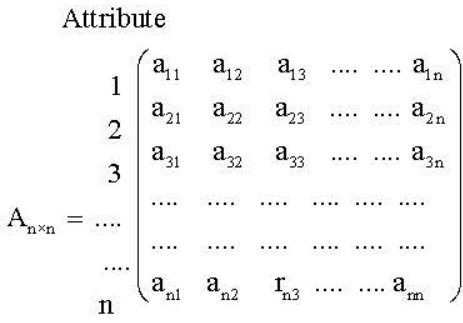

Step 3: Construct normalized decision matrix: 


$$
\begin{aligned}
& \mathrm{C}_{\mathrm{ij}}=\frac{\mathrm{a}_{\mathrm{ij}}}{\sum_{\mathrm{J}=1}^{\mathrm{n}} \mathrm{a}_{\mathrm{ij}}} \\
& \mathrm{i}=1,2,3, \ldots, \mathrm{n}, \mathrm{j}=1,2,3, \ldots, \mathrm{n}
\end{aligned}
$$

Step 4: Construct the weighted, normalized decision matrix:

$$
\mathrm{w}_{\mathrm{i}}=\sum_{\mathrm{J}=1}^{\mathrm{n}} \mathrm{cij} / \mathrm{n}, \mathrm{i}=1,2,3, \ldots, \mathrm{n}
$$

Step 5: Calculate eigenvector and row matrix:

$$
\begin{gathered}
E=\text { Nth rootvalue } / \sum N \text { th rootvalue } \\
\text { Row matrix }=\sum_{\mathrm{J}=1}^{\mathrm{n}} \mathrm{a}_{\mathrm{ij}} \times \mathrm{e}_{\mathrm{j} 1}
\end{gathered}
$$

Step 6: Calculate the maximum eigenvalue, $\lambda_{\max }$ :

$$
\lambda_{\max }=\text { Rowmatrix/E }
$$

Step 7: Calculating the consistency index and consistency ratio:

$$
\begin{gathered}
\mathrm{CI}=\frac{\lambda_{\max }-n}{\mathrm{n}-1} \\
\mathrm{CI}=\frac{\mathrm{CI}}{\mathrm{RI}}
\end{gathered}
$$

where, $\mathrm{n}$ and RI denote the number of attributes and randomly generated consistency index, respectively (Saaty, 2008; Coyle, 2004). Steps 8-12 are related to VIKOR method.

Step 8: Determine the best $\mathrm{f}_{\mathrm{i}}{ }^{*}$ and the worst $\mathrm{f}_{\mathrm{i}}^{-}$values of all criterion functions. Assuming that ith function represents a benefit:

$$
f_{i}^{*}=\max _{j} f_{i j} \quad f_{i}^{-}=\max _{j} f_{i j}
$$

Step 9: Compute the values $S_{j}$ and $R_{j}, j=1,2, \ldots, J$ by the relations:

$$
\begin{aligned}
& S_{j}=\sum_{i=1}^{n} w_{i}\left(f_{i}^{*}-f_{i j}\right) /\left(f_{i}^{*}-f_{i}^{-}\right) \\
& R_{j}={ }_{i}^{m a x}\left[w_{i}\left(f_{i}^{*}-f_{i j}\right) /\left(f_{i}^{*}-f_{i j}^{-}\right)\right]
\end{aligned}
$$

where, $\mathrm{w}_{\mathrm{i}}$ are the weights of criteria, expressing their relative importance.

Step 10: Compute the values $Q_{j}, j=1,2, \ldots, J$ by the relation:

$$
\begin{gathered}
Q_{j}=\frac{v\left(S_{j}-S^{*}\right)}{S^{-}-S^{*}}+\frac{(1-v)\left(R_{j}-R^{*}\right)}{R^{-}-R^{*}} \\
S^{*}=\min _{j} S_{j} \quad S^{-}=\min _{j} S_{j} \\
R^{*}=\min _{j} R_{j} \quad R^{-}=\min _{j} R_{j}
\end{gathered}
$$

And $v$ is introduced as weight of the strategy of "the majority of criteria" (or "the maximum group utility") here $\mathrm{v}=0.5$.

Step 11: Rank the alternative, sort by the values $S, R$ and $\mathrm{Q}$ in a descending order. The results are three ranking list.

Step 12: Proposed as a compromised solution, for given criteria weights, the alternative (a') which is the best ranked by the measure $Q$ (minimum)if the following two conditions are satisfied:

\section{C1; “Acceptable advantage":}

$$
Q\left(a^{\prime \prime}\right)-Q\left(a^{\prime}\right) D Q
$$

where, a" is the alternative with second position in the ranking list by:

$$
\mathrm{Q} ; \mathrm{DQ}=\frac{1}{\mathrm{~J}-1}
$$

where, $\mathrm{J}$ is the number of alternatives.

C2; "Acceptable stability in decision making": Alternative a must also be the best ranked by $\mathrm{S}$ or/and $\mathrm{R}$. This compromise solution is stable within a decision making process which could be: "voting by majority rule" (when $v>0: 5$ is needed) or "by consensus" $v-0: 5$ or "with veto" $(\mathrm{v}<0: 5)$. Here, $\mathrm{v}$ is the weight of the decision making strategy "the majority of criteria" (or "the maximum group utility"). If one of the conditions is not satisfied then a set of compromise solutions is proposed which consists of:

- Alternatives a' and a" if only condition C2 is not satisfied

- Alternatives a', a", .., $\mathrm{a}^{(\mathrm{M})}$ if condition $\mathrm{Cl}$ is not satisfied and $\mathrm{a}^{(\mathrm{M})}$ is determined by the relation:

$$
\mathrm{Q}\left(\mathrm{a}^{(\mathrm{M})}\right)-\mathrm{Q}\left(\mathrm{a}^{\prime}\right)<\mathrm{DG}
$$

For Maximum $\mathrm{M}$ (the positions of these alternatives are "in closeness"). In the following study, we apply the proposed model to a list of web services obtained from the QWS dataset (Al-Masri and Mahmoud, 2008). 


\section{RESULTS AND DISCUSSION}

The QWS dataset contains 2507 web services that exist on the web. For the purpose of testing our model, five web services were selected from the data set. The selection was based on the fact they all had the same functional requirements but different values of the QoS attributes. The QoS attributes are response time, throughput rate, latency, availability and reliability. Applying the AHP process to these web services, we obtain the pairwise comparison matrix Table 2 and the normalized comparison matrix Table 3 of the five selected web services.

Calculation of the criteria weights using AHP: AHP method is utilized to determine the criteria weights which are used during the evaluation process.

The service consumer enters preferences which are formulated to a pairwise comparison matrix using the scale shown in Table 1. The pairwise comparison matrix in Table 2 shows the user preference.

The pairwise comparison matrix is normalized before the weights can be calculated. We calculated the relative weights as shown in Table 3 by using the normalized matrix and obtaining the average value with the help of Eq. 1 and 2.
The consistency ratio of the pairwise comparison matrix is calculated with the help of Eq. 3-7 which we found to be 0.08 which is $<0.10$. Therefore, the weights of criteria are consistent and can be used in the process of web service selection.

Having obtained the weights of the various QoS, we apply VIKOR method to determine the rankings of the alternatives. The computed weights as shown in Table 4 are used as input in the ranking process.

The averages of the QoS attributes measurements as obtained from the QWS dataset for the five web services are presented in Table 5 .

Applying Eq. 8 to data presented in Table 5, we obtain the best $\mathrm{f}_{i}^{*}$ and worst $\mathrm{f}_{i}^{-}$values for each column. This is shown in Table 6.

As the measurements present in the QWS dataset are not within the same scale, we need to normalize the data. The normalized matrix is shown in Table 7 .

The normalized matrix in Table 7 is used to calculate the $S_{j}$ and $R_{j}$ with the help of Eq. 9 and 10. The values of $S_{j}$ and $R_{i}$ are shown in Fig. 2.

In the next step, we calculate $\mathrm{S}^{-}, \mathrm{S}^{+}, \mathrm{R}^{-}$and $\mathrm{R}^{+}$in order to compute the index values $\mathrm{Q}_{\mathrm{j}}$. These are the maximum and minimum values in $\mathrm{S}_{\mathrm{j}}$ and $\mathrm{R}_{\mathrm{j}}$, respectively and are computed by applying Eq. 11 and 12. The $Q_{j}$ values are shown in Table 8 :

Table 2: Pairwise comparison matrix

\begin{tabular}{lccccc}
\hline Variables & Response time & Throughput & Latency & Availability & Reliability \\
\hline Response time & 1.00 & 1.00 & 6.00 & 0.20 & 0.33 \\
Throughput & 1.00 & 1.00 & 6.00 & 0.17 & 0.25 \\
Latency & 0.17 & 0.17 & 1.00 & 0.14 & 0.17 \\
Availability & 5.00 & 6.00 & 7.00 & 1.00 & 2.00 \\
Reliability & 3.00 & 4.00 & 6.00 & 0.50 & 1.00 \\
\hline
\end{tabular}

Table 3: Normalized comparison matrix and calculated weights for five criteria

\begin{tabular}{lcccccr}
\hline Variables & Response time & Throughput & Latency & Availability & Reliability & Calculated weight (\%) \\
\hline Response time & 0.10 & 0.08 & 0.23 & 0.10 & 0.09 & 11.99 \\
Throughput & 0.10 & 0.08 & 0.23 & 0.08 & 0.07 & 11.22 \\
Latency & 0.02 & 0.01 & 0.04 & 0.07 & 0.04 & 3.68 \\
Availability & 0.49 & 0.49 & 0.27 & 0.50 & 0.53 & 45.70 \\
Reliability & 0.30 & 0.33 & 0.23 & 0.25 & 0.27 & 27.40 \\
Sum & 1.00 & 1.00 & 1.00 & 1.00 & 1.00 & 100.00 \\
\hline
\end{tabular}

Table 4: Weights based on user preference

\begin{tabular}{lccccc}
\hline Criteria & Response time & Throughput & Latency & Availability & Reliability \\
\hline Weights & 11.99 & 11.22 & 3.68 & 45.70 & 27.40 \\
\hline
\end{tabular}

Table 5: Web service attributes measurements from the QWS dataset

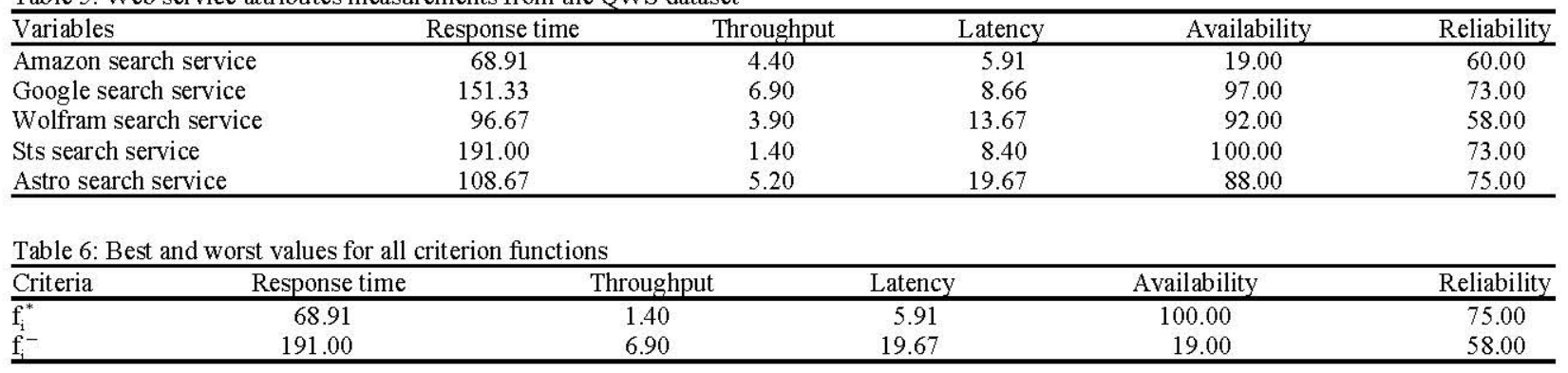


Table 7: Normalized matrix from attributes measurements found in the dataset

\begin{tabular}{lccccc}
\hline Variables & Response time & Throughput & Latency & Availability & Reliability \\
\hline Amazon search service & 0.00 & 6.12 & 0.00 & 45.70 & 24.18 \\
Google search service & 8.10 & 11.22 & 0.74 & 1.69 & 3.22 \\
Wolfram search service & 2.73 & 5.10 & 2.08 & 4.51 & 27.40 \\
Sts search service & 11.99 & 0.00 & 0.67 & 0.00 & 3.22 \\
Astro search service & 3.91 & 7.75 & 3.68 & 6.77 & 0.00 \\
\hline
\end{tabular}

Table 8: Values of $\mathrm{Q}$;

Variables

Amazon search service

Google search service

Wolfram search service

Sts search service

Astro search service

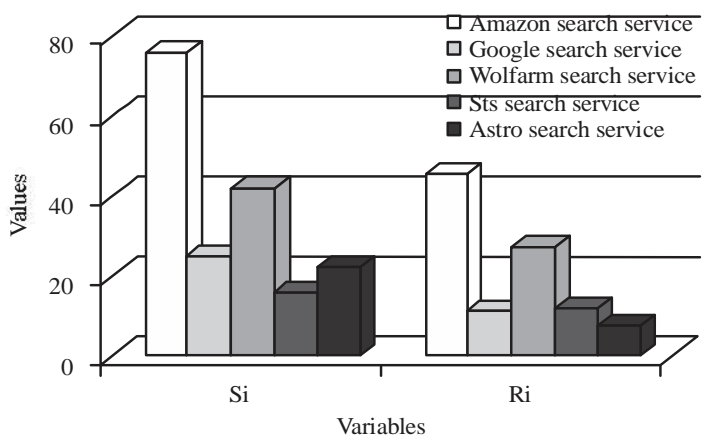

Fig. 2: Values of $S_{j}$ and $R_{j}$

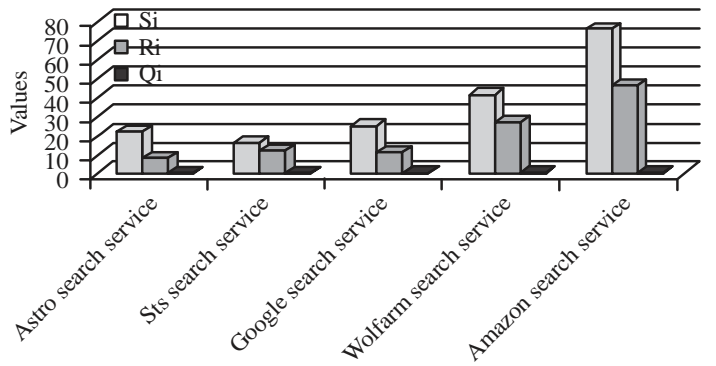

Fig. 3: Values of $S_{j}, R_{j}$ and $Q_{j}$

$$
\mathrm{S}^{-}=76.00, \mathrm{~S}^{*}=15.88, \mathrm{R}=45.70, \mathrm{R}^{*}=7.75
$$

The $S_{j}, R_{j}$ and $Q_{j}$ are ranked in a descending order and displayed in Fig. 3. As a final step in the process to determine the compromised solution, we need to establish whether both conditions ( $\mathrm{Cl}$ and $\mathrm{C} 2$ ) are satisfied (Step 12 listed above). We apply both conditions for Astro search service (as $Q$ is minimum).

\section{C1 is not satisfied:}

$$
\begin{aligned}
& \mathrm{DQ}=1 /(5-1)=0.25 \\
& 0.06-0.05 \geq 0.25
\end{aligned}
$$

C2 is satisfied: Astro search service dominates the best ranking in $S_{j}$ only. In this case, one of the conditions which is $\mathrm{Cl}$ was not satisfied and then a compromised solution is proposed using Eq. 15:

$$
\begin{aligned}
& \mathrm{Q}\left(\mathrm{a}^{2}\right)-\mathrm{Q}\left(\mathrm{a}^{1}\right)=0.06-0.05=0.01<\mathrm{DQ} \\
& \mathrm{Q}\left(\mathrm{a}^{3}\right)-\mathrm{Q}\left(\mathrm{a}^{1}\right)=0.12-0.05=0.07<\mathrm{DQ} \\
& \mathrm{Q}\left(\mathrm{a}^{4}\right)-\mathrm{Q}\left(\mathrm{a}^{1}\right)=0.47-0.05=0.42>\mathrm{DQ}
\end{aligned}
$$

For an alternative to have an added advantage over another, the minimum difference between the $Q$ values should be DQ that is 0.25 in this case. It can be strongly concluded that a particular alternative is the best one if the difference between the $Q$ values of the 1st alternative and 2nd alternative is 0.25 . The third alternative which is Google search service has an added advantage in the compromised group because the difference between the $\mathrm{Q}$ values of Google search service and Astro search service is closer to DQ.

\section{CONCLUSION}

As there are several web services offering similar functions, with different QoS parameters. The selection of suitable web service becomes a challenging for users. To select an appropriately among different service, users look for QoS parameters of web services. In this study, we present a hybrid model for web service selection using AHP and VIKOR. In this study, AHP is used to determine the weights of QoS parameters and VIKOR method is applied to rank the web services. Finally, in order to demonstrate how the proposed model can be applied on web service selection, we provided an example using QoS criteria and web services measurements from QWS data set. The results show that Google search service performed better than other web search services under the selected QoS requirements, our approach can select the most suitable service.

\section{RECOMMENDSTIONS}

For future work, we wish to compare the results as obtained by our proposed model with other a replicated study of our proposed model with other MCDM method such as TOPSIS, ELECTRE and PROMETHEE.

\section{REFERENCES}

Aiello, M. and P. Giorgini, 2004. Applying the Tropos methodology for analysing web services requirements and reasoning about qualities of services. Ph.D Thesis, University of Trento, Trento, Italy. 
Al-Masri, E. and Q.H. Mahmoud, 2008. Investigating web services on the world wide web. Proceedings of the 17th International Conference on World Wide Web, April 21-25, 2008, Beijing, China, pp: 795-804.

Aljazzaf, Z.M., M.A.M. Capretz and M. Perry, 2016. Trust-based service-oriented architecture. J. King Saud Univ. Comput. Inf. Sci., 28: 470-480.

Athawale, V.M., P. Chatterjee and S. Chakraborty, 2010. Selection of industrial robots using compromise ranking method. Proceedings of the 2010 International Conference on Industrial Engineering and Operations Management, January 9-10, 2010, Dhaka, Bangladesh, pp: 1-8.

Belouaar, H., O. Kazar and K. Rezeg, 2017. Web service selection based on TOPSIS algorithm. Proceedings of the 2017 International Conference on Mathematics and Information Technology (ICMT), December 4-5, 2017, IEEE, Adrar, Algeria, ISBN:978-1-5386-3270-3, pp: 177-182.

Benatallah, B., R.M. Dijkman, M. Dumas and Z. Maamar, 2005. Service-Composition: Concepts, Techniques, Tools and Trends. In: Service-Oriented Software System Engineering: Challenges and Practices, Stojanovic, Z. and A. Dahanayake (Eds.). IGI Global, Pennsylvania, USA., ISBN-13:9781591404262, pp: 48-67.

Benitez, J., X. Delgado-Galvan, J.A. Gutierrez and J. Izquierdo, 2011. Balancing consistency and expert judgment in AHP. Math. Comput. Modell., 54: $1785-1790$.

Brown, A., S. Johnston and K. Kelly, 2002. Using service-oriented architecture and component-based development to build web service applications. Rational Software Corporation, San Jose, California, USA, pp: 1-16. http://dit.isuct.ru/Publish_RUP/ soa.rup_soma/guidances/whitepapers/resources/usi ng_soa_and_cbd_to_build_ws_applications.pdf

Buyukozkan, G. and A. Gorener, 2015. Evaluation of product development partners using an integrated AHP-VIKOR model. Kybernetes, 44: 220-237.

Chang, T.H., 2014. Fuzzy VIKOR method: A case study of the hospital service evaluation in Taiwan. Inf. Sci., 271: 196-212.

Coyle, G., 2004. The Analytic Hierarchy Process (AHP). In: Practical Strategy: Structured Tools and Techniques, Coyle, G. (Ed.). Pearson Education Ltd., Glasgow, Scotland, ISBN-13: 9780273682202 , pp: $1-11$.

Dragoni, N., 2009. Toward trustworthy web services-approaches, weaknesses and trust-bycontract framework. Proceedings of the 2009 IEEE/WIC/ACM International Joint Conference on Web Intelligence and Intelligent Agent Technology (WI-IAT'09) Vol. 03, September 15-18, 2009, IEEE Computer Society, Washington, DC., USA., ISBN:978-0-7695-3801-3, pp: 599-606.
Kaewbanjong, K. and S. Intakosum, 2015. QoS attributes of web services: A systematic review and classification. J. Adv. Manage. Sci., 3: 194-202.

Kumar, R.D. and G. Zayaraz, 2011. A Qos aware quantitative web service selection model. Int. J. Comput. Sci. Eng., 3: 1534-1538.

Kumar, R.R. and C. Kumar, 2016. An evaluation system for cloud service selection using fuzzy AHP. Proceedings of the 2016 11th International Conference on Industrial and Information Systems (ICIIS), December 3-4, 2016, IEEE, Roorkee, India, ISBN:978-1-5090-3819-0, pp: 821-826.

Lall, M., 2013. A methodology for the formalization of non-functional requirements for web services. Ph.D Thesis, University of South Africa, Pretoria, South Africa.

Lall, M., J.V.D. Poll and L. Venter, 2012. Towards a formal definition of availability of web services. Proceedings of the International Conference on Computing, Networking and Digital Technologies (ICCNDT2012), November 11-13, 2012, Sanad, Bahrain, pp: 273-284.

Lall, M., L.M. Venter and J.A. Van der Poll, 2010. Evaluating the second generation Web services specifications for satisfying non-functional requirements. Proceedings of the World Conference on E-Learning in Corporate, Government, Healthcare and Higher Education, October 18, 2010, Orlando, Florida, USA., pp: 1919-1929.

Liu, H. and T. Yan, 2007. Bidding-evaluation of construction projects based on VIKOR method. Proceedings of the 2007 IEEE International Conference on Automation and Logistics, August 18-21, 2007, IEEE, Jinan, China, ISBN:978-1-4244-1530-4, pp: 1778-1782.

Maheswari, S. and G.R. Karpagam, 2015. Enhancing fuzzy topsis for web service selection. Intl. J. Comput. Appl. Technol., 51: 344-351.

Mani, A. and A. Nagarajan, 2002. Understanding quality of service for web services: Improving the performance of your web services. IBM, Armonk, New York, USA. https://www.ibm.com/ developerworks/library/ws-quality/index.html

Opricovic, S. and G.H. Tzeng, 2004. Compromise solution by MCDMmethods: A comparative analysis of VIKOR and TOPSIS. Eur. J. Operat. Res., 156: 445-455.

Purohit, L. and S. Kumar, 2018. A classification based web service selection approach. IEEE. Trans. Serv. Comput., 1: 1-1.

Russo, R.D.F.S.M. and R. Camanho, 2015. Criteria in AHP: A systematic review of literature. Procedia Comput. Sci., 55: 1123-1132. 
Saaty, T.L., 1987. The analytic hierarchy process-what it is and how it is used. Math. Modeling, 9: 161-176.

Saaty, T.L., 2008. Decision making with the analytic hierarchy process. Int. J. Serv. Sci., 1: 83-98.

Sun, M. T. Zang, X. Xu and R. Wang, 2013. Consumer-centered cloud services selection using AHP. Proceedings of the 2013 International Conference on Service Sciences (ICSS), April 11-13, 2013, IEEE, Shenzhen, China, ISBN:978-1-4673-6258-0, pp: 1-6.
Tzeng, G.H., M.H. Teng, J.J. Chen and S. Opricovic, 2002. Multicriteria selection for a restaurant location in Taipei. Int. J. Hosp. Manage., 21: 171-187.

Zhang, L., H. Zou and F. Yang, 2011. A dynamic web service composition algorithm based on TOPSIS. J. Networks, 6: 1296-1304.

Zuo, M., S. Wang and B. Wu, 2008. Research on web services selection model based on AHP. Proceedings of the 2008 IEEE International Conference on Service Operations and Logistics, and Informatics Vol. 2, October 12-15, 2008, IEEE, Beijing, China, ISBN:978-1-4244-2012-4, pp: 2763-2768. 